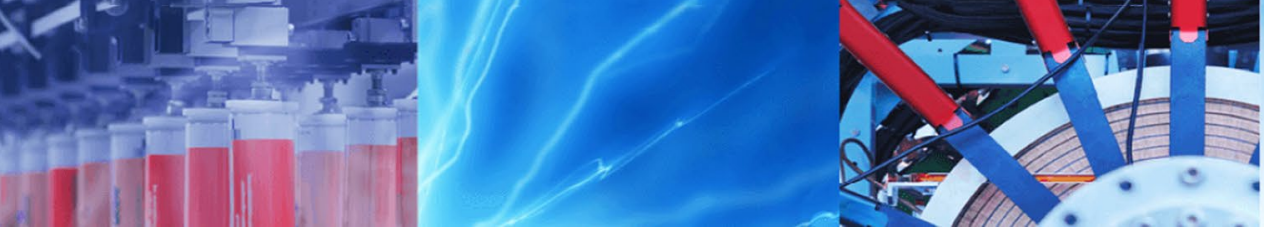

Research Article

\title{
A demand side management control strategy using Whale optimization algorithm
}

\author{
Ankit Kumar Sharma $^{1}$ D $\cdot$ Akash Saxena $^{1}$
}

(c) Springer Nature Switzerland AG 2019

\begin{abstract}
In recent years, demand side management programs are in the spotlight due to the evolution of the smart grid and consumer-centric policies. Demand side management program contains many objectives one of the prime objective is to manage energy demand by certain change in consumer demand. This can be achieved by various methods such as financial discount and change in behavior through imparting education to support the stressed conditions of the grid. This paper demonstrates demand side management strategies based upon strategic conservation, peak clipping and load shifting techniques for future smart grids. The grid contains large number of controllable devices. The day before strategic conservation, peak clipping and load shifting techniques discussed in this paper are mathematically derived for minimization problem. A heuristic-based Whale optimization algorithm (WOA) was developed for solving this problem of minimization. Simulations are conducted on a test smart grid that contains a variation in loads in two service areas, one with residential consumers, and another with commercial consumers. WOA proves its efficacy by comparing the results with spider monkey optimization and biogeography based optimization. The simulation results show that proposed demand side management strategies achieve substantial savings, while reducing the peak load demand of the smart grid.
\end{abstract}

Keywords Demand side management · Demand response - Whale optimization algorithm · Load shifting · Strategic conservation and peak clipping $\cdot$ Spider monkey optimization and biogeography based optimization

\section{Introduction}

Smart Grid [1, 2] constitute a perception of the next generation power systems associated with various control and sensing technologies, with effective communication at transmission and distribution side to fulfill optimal demand in a foolproof way. The important features [2] of modern grid, according to US Energy grid report are consumer comity, fool proof healing ability, resistance ability during faulty condition, potential to use generation options with storage, market dependent well organized operations and better power caliber in optimal way. This advance grid is motivated by several techno-economical and socio-economical factors in association with environmental benefits.
Demand Response (DR) can be given as the adjustment in usage of electricity by end users from their normal daily utilization figures for changes in price of electricity during that time. Advance definition of DR is given by "designing the incentive payments to engender minimum use of electricity at the same time when market prices are high or system reliability is under the threat" [3].

Consumers can respond in three ways [3-7]:

1. Reduce consumption at targeted times but maintain same consumption figures at other times. This type of respond has a temporary loss of consumer's comfort.

2. Shift consumption from targeted times to other time cycle so that overall consumption is the same; or

$\triangle$ Akash Saxena, aakash.saxena@hotmail.com; akash@skit.ac.in; Ankit Kumar Sharma, ankit.krishnaa@gmail.com |'Department of Electrical Engineering, Swami Keshvanand Institute of Technology, Management \& Gramothan, Jaipur 302017, India.

SN Applied Sciences (2019) 1:870 | https://doi.org/10.1007/s42452-019-0899-0 


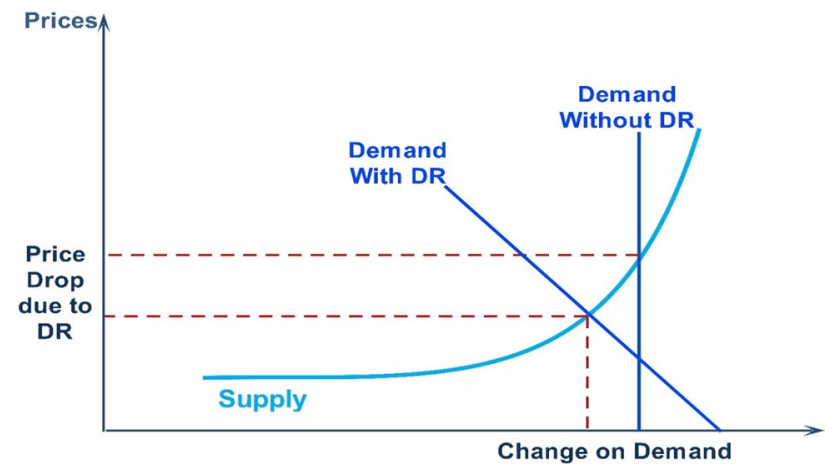

Fig. 1 A simplified graph of the electricity market with and without DSM

3. Use on-site generation.

In electricity system should be a ideal coordination between supply and demand in real time for modest operation but there is complexity i.e. the level of supply and demand usually change briskly due to many reasons involve, generation unit outages, line outages at transmission and distribution side and quick changes in load. The infrastructure of power system is heavily capital accelerated; so DR is one of the cheapest resources available for optimal operation of the system [3]. Another important and main market profit is the reduction in price volatility in the wholesale market. A small depletion in demand will result in a big depletion in cost of generation and electricity price in real time, as shown in Fig. 1.

\subsection{Classifications of demand response program}

Various DR programs are shown in Fig. 2. DR programs can be divided into two main categories, Despatchable or Incentive Based Programs (IBP) and Non Despatchable or Price Based Programs (PBP) [3, 8]. Despatchable programs are further classified into two categories, classical and market based programs. Classical programs include Direct Load Control (DLC) and Interruptible or Curtailable services (I/Cs). Market based programs divided into four categories; Emergency DR Programs (EDRP), Demand Bidding (DB), Capacity Market Programs (CMP) and Ancillary services market Programs (ASMP).

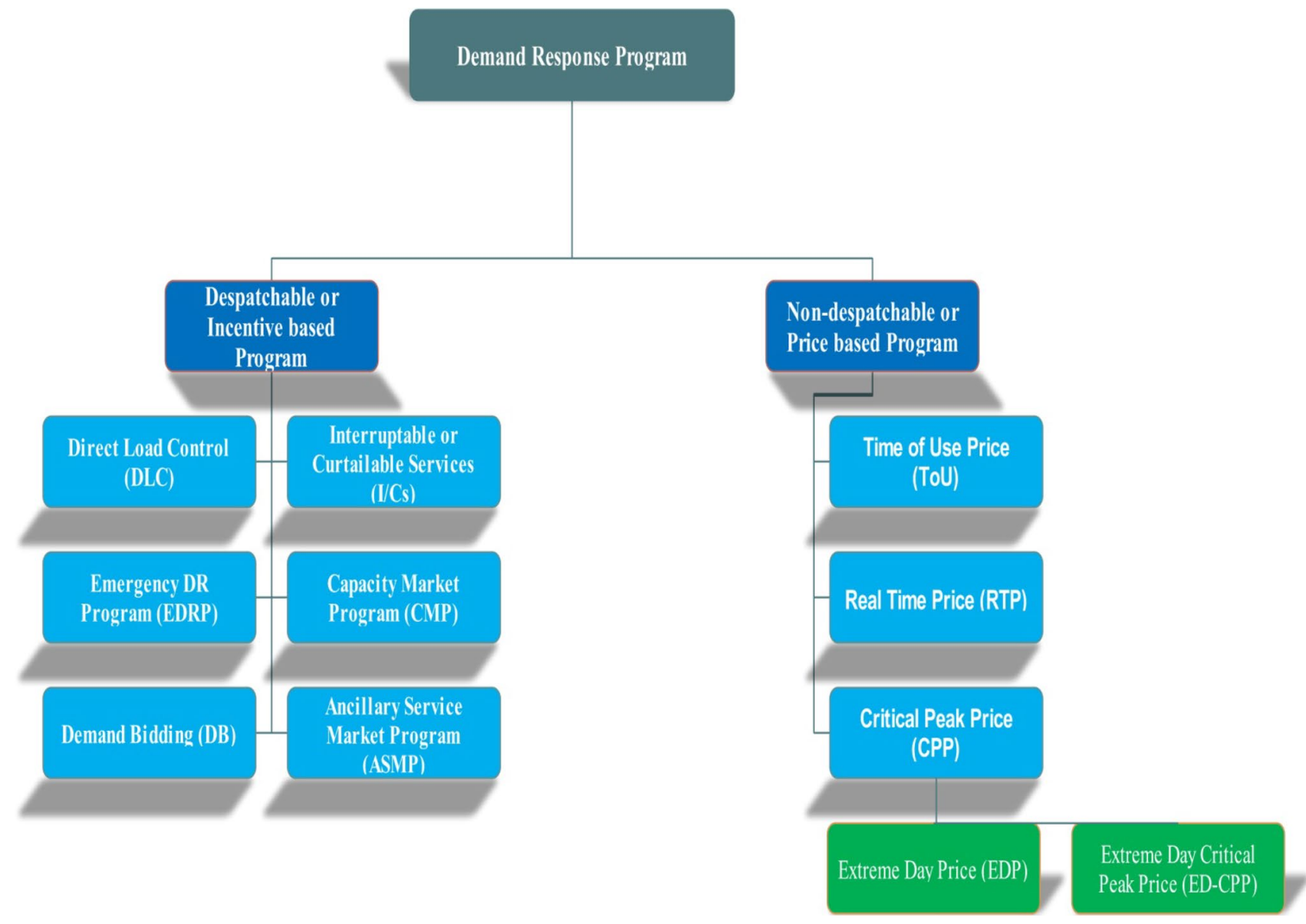

Fig. 2 Classification of DR programs 
PBP programs are based on spirited pricing rates i.e. electricity prices rates fluctuate hourly and not follow the flat rate pattern. These rates classified into three main categories, Time of Use (TOU) price, Real Time Pricing (RTP) and Critical Peak Price (CPP) which is further divided into two categories; Extreme Day Price (EDP), Extreme CPP (ED-CPP).

\subsection{Demand response benefits}

Figure 3 shows the benefits related to DR. They divided into four categories: participant side, market side, in term of reliability and market performance.

The profits of DR programs are not only for participants welfare but also some are market focused, e.g. the reduction of overall demand results in reduction in expenses of newly installed generating units. Reliability assets can be considered as one of the market-focused aid because they affected the all programs participants [9].

The last category of DR program is improving electricity market performance [10]. Consumers can control the power of market using market based programs and spirited pricing programs $[11,12]$.
A brief literature survey to understand the concept and applications of demand side management/demand response is presented in the following sections:

\subsection{Wind and renewable integration}

Demand response has been studied broadly as a tool to enable better, more efficient integration of wind and other renewable generation resources. The dynamic recurring, uncertainty, variability and volatility of wind can be prevented with demand response in a fast and cost-effective manner [13-18].

\subsection{Market and remuneration}

It demonstrated the procedure in which the power detachment on the consumer side is rewarded. It can be divided as price based, incentive based and combination of both called hybrid. In PBP, users lower their uses according to the spirited change price imposed by operator or by the energy stock market. IBP assume that users are separately or conjointly committed to lower their consumption during a certain peak time period. Price based and incentive based methods are collectively called hybrid DR program [19-23].

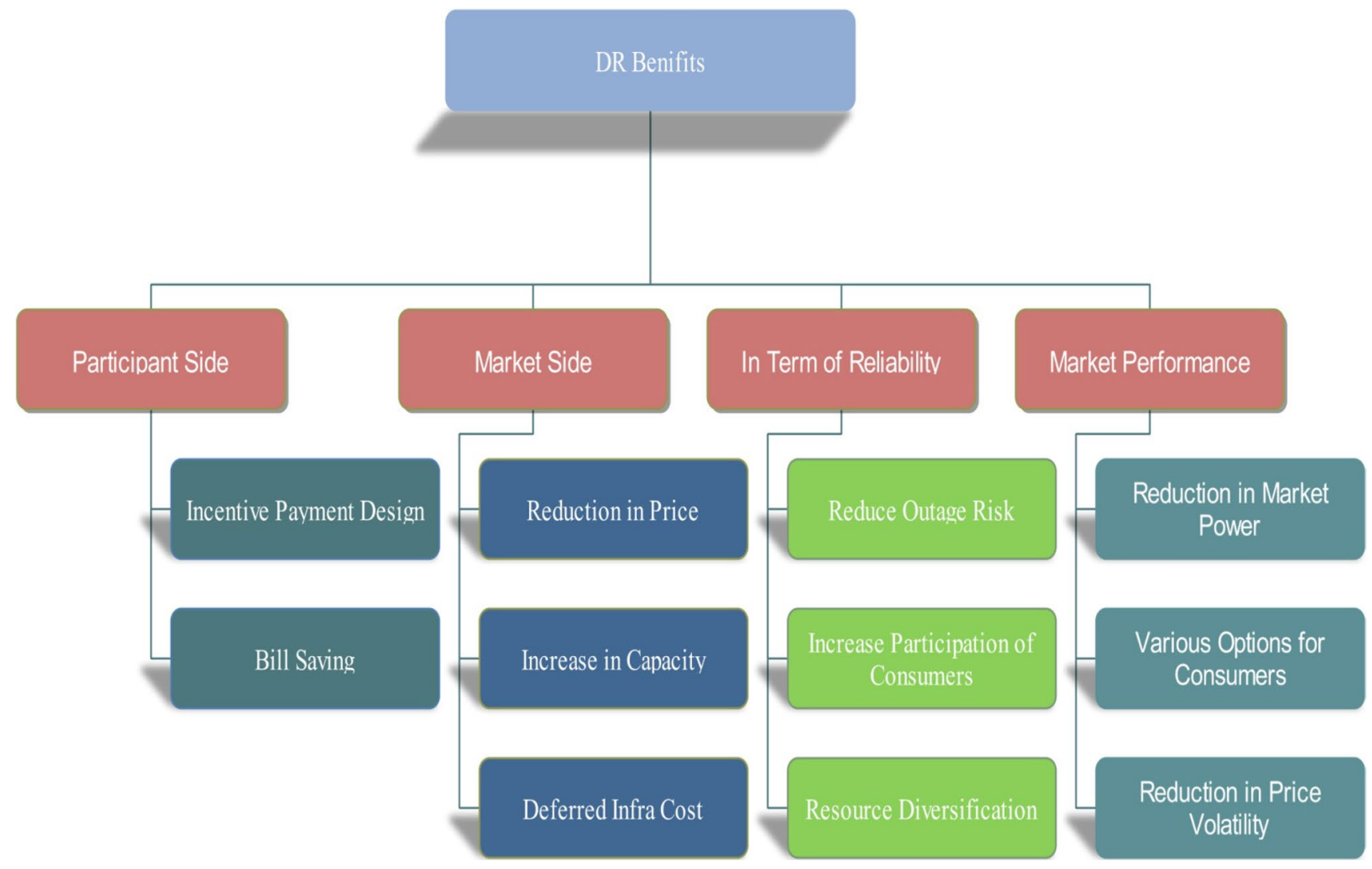

Fig. 3 Benefits related to DR 


\subsection{Behavioral analysis of different types of users}

The classification of the participating consumers can be entrenched based on behavioral analysis of users and precedent that go from average level consumption to techno-economic and socio-economic level. In it, the distribution has been facilitating according to the types of user [24-28].

The rest sections of the paper are organized in the following way: In Sect. 2, details of Demand Side Management techniques and demand side management strategy: problem formulation and proposed algorithm are given, in Sect. 3, details of smart grid is given, in Sect. 4, results and discussions are presented, in Sect. 5. Last but not the least, the major findings of the work is reported in conclusion section.

\section{Techniques used in demand side management}

DSM alters the electricity consumption to yield the desired changes in the load contour at distribution side. To avoid the peak demand, DSM concentrates [29] on power saving methodologies, electricity rates, fiscal incentives and user/ environment friendly government policies. Due to increase in electricity demand, system become unstable and to avoid this instabilities, a worthy goal of demand side management finalized that could be to alter the configuration of the load curve by lowering and shifting the total load demand at distribution side during peak load periods in sequence to reduce the final tariff of electricity. So the system requires an enlightened coordination between operators and consumers. The load configurations which show the daily electric demands of residential, commercial and industrial consumers between peak time and off peak times can be changed by means of six broad methods [29, 30]: peak clipping, load shifting, valley filling, load growth, strategic conservation and flexible load curve. These six topologies of demand side management are shown in Fig. 4. Peak clipping and valley filling methods focused on leveling the peak and valley load levels to avert the anxiety of insecurity of smart grid. Peak clip method [29, 30] is a direct load control (DLC) method. Load shifting [29, 30] is globally applied effectively as load management technique by shifting the loads from peak consumption time to off peak consumption time. Strategic conservation [29] intends to apply demand curtail methods directly at customer houses, to achieve load shape optimization. Strategic load growth $[29,30]$ approximate equals to valley fill technique but it used in case of large demand to optimizes the daily response. Flexible load shape $[29,30]$ is mainly associated to smart grid reliability. Smart grid management systems (SGMS) find the customers with flexible controlled loads during peak load in trading for various financial incentives or rewards.
Fig. 4 Demand side management techniques
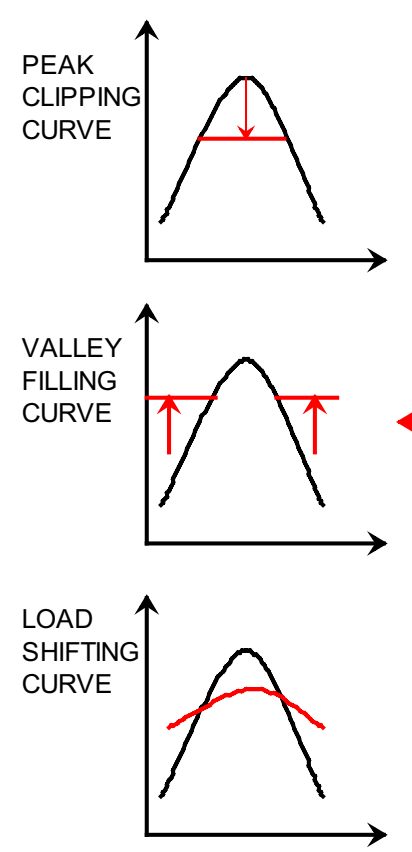

STRATEGIC

个CONSERVATION
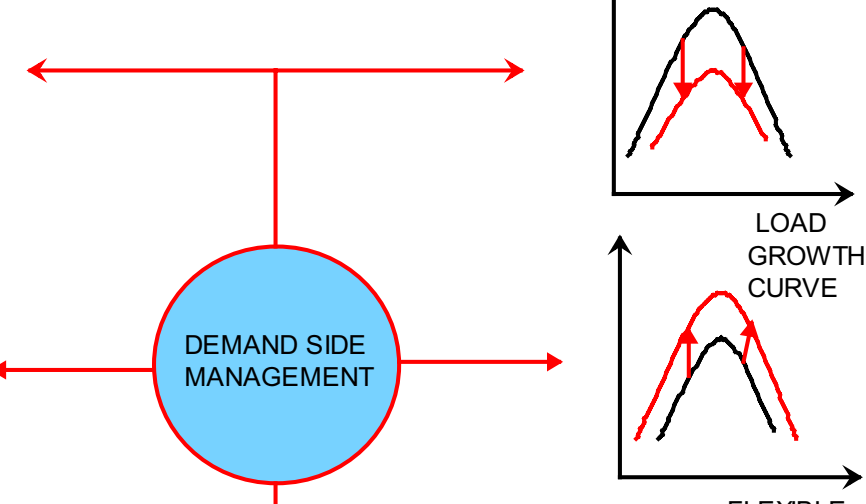

FLEXIBLE

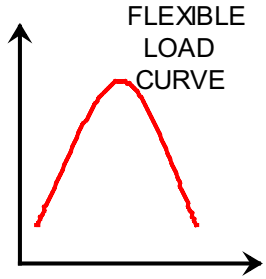

SN Applied Sciences 


\section{Used demand response technique}

This paper demonstrated a generalized application of DSM strategy for controlling advanced future grid. It uses strategic conservation, peak clipping and load shifting as the main techniques that can be used and controlled by grid engineer. Goal of the DSM techniques could be minimizing power uses or reduces the peak demand. Future Smart grid engineer designs an objective load curve which guides the path to fulfill the final objective of the demand response.

\subsection{Problem formulation}

In sequence of applying various DSM programs analytical and optimization tools have been used [31]. The proposed DSM strategy operates the connection moments of each device such a way that brings the load consumption curve near as possible to objective curve.

The main purpose of optimization algorithm is tried to overlap the final load curve with objective load curve [32]. Proposed load clipping technique is mathematically formulated as follows:

$$
\begin{gathered}
\text { Minimize } \\
\sum_{i=1}^{n}(\operatorname{PLoad}(t)-\text { Objective }(t))^{2}
\end{gathered}
$$

where objective (t) is the value of the objectives at time $\mathbf{t}$, and $\mathbf{P}$ Load $(\mathbf{t})$ is the actual consumption at time $\mathbf{t}$.

In the case of Strategic Conservation and Peak Clipping, $\mathbf{P}$ Load $(\mathbf{t})$ is given by the following equation:

$\sum_{i=1}^{N} \sum_{j=1}^{D} X_{i} X_{j}+\sum_{i=1}^{N} \sum_{j=1}^{D}\left(1-X_{i}\right)\left(X-X_{j}\right)$

where switching status of devices is from $\mathrm{i}$ to $\mathrm{N}$, class or types of device given by $\mathrm{j}$ to $\mathrm{D}$. $\mathrm{X}$ represent the total number of devices of a class.

In the case of Load Shifting, P Load (t) is given as:

$$
\text { PLoad }(t)=\text { Forecast }(t)+\text { Connect }(t)-\text { Disconnect }(t)
$$

where Forecast $(t)$ is the forecasted load at time $t$, and Connect $(t)$ and Disconnect $(t)$ are the amount of loads Connect and Disconnect at time t.

\subsection{Whale optimization algorithm}

Optimization can be defined as, under the given constraints finding the most cost effective outputs by maximizing the desired factors and minimizing the undesired ones i.e. maximum yields in minimum efforts. Recent year's application of metaheurestic techniques is increased in real problems and used by researchers in various applications. Bansal, Jagdish Chand et al. [33] developed Spider Monkey Optimization which was based on the social behavior of spider monkeys and Simon, Dan [34] developed Biogeography Based Optimization which was based on Biogeography is the study of the geographical distribution of biological organisms. Saxena Akash et al. [35] used a radial basis function neural network based optimization technique for optimal placement and sizing of DG, also performed a comprehensive study of chaos embedded bridging mechanisms and crossover operators for grasshopper optimization in [36], ambient air quality classification using Grey Wolf Optimization (GWO) in [37] and used Gravitational Search Algorithm (GSA) for optimal allocation of SVC in [38]. These researches are evidences of applications solved through bio inspired optimization techniques.

Whale optimization algorithm (WOA) [39] type of metaheuristic algorithm has been introduced by Mirjalili and Lewis. The whales are an intelligent mammal with emotion, judgment and social behavior. Big inspiration to construct the WOA, behavior of unique hunting of humpback whales has been used. Krill's and small fishes near to the sea surface are food of humpback whale. Humpback whales are used a special hunting technique called bubbles net method. In this technique whales swim around their prey and make distinctive bubbles forming circles, which help whales to attack on prey. The working of WOA is divided in the following sections: Encircling the prey, Hunting method and Search for prey.

The main problem associated with WOA is moderate convergence speed so to get better performance chaotic WOA used in [40] and Hyper-heuristic approach used in [41]. Apart from engineering problem, WOA used in wrapper feature selection [42], in constrained engineering problem [43], in parameter extraction of solar PV models [44], in weak feature extraction from multi component signal [45], to sustain the balance between exploration and exploitation [46], in optimal reactive power dispatch [47], to enhance the power system stability [48], in cost minimization of Micro-Grid [49], in analysis and forecasting of the carbon price [50]. These wide applications motivated authors to develop a demand side management based strategy on the basis of WOA

Pseudo code for WOA algorithm is illustrated in Algorithm 1. Whale Optimization Algorithm has been gained a lot of interest, now a day due to following reasons:

- Less number of control parameter.

- Simple to structure and easy to implement.

- Less chances of local minima entrapment.

- A slow but effective convergence speed. 
Algorithm 1. Pseudo code of Whale Optimization Algorithm

Initialize the whales population $\mathrm{X}_{\mathrm{i}}(\mathrm{i}=1,2,3, \ldots \ldots \mathrm{n})$

Evaluate the fitness of each search agent to find the best search agent $\mathbf{X}^{*}$

$\mathbf{X}^{*}=$ Best search agent

while $(\mathrm{t}<$ maximum number of iterations)

for each search agent

Update $\mathbf{a}, \mathbf{A}, \mathbf{I}$ and $\mathbf{p}$

ifl $(\mathrm{p}<0.5)$

if $2(|A|<1)$

Update the position of the current search agent

else if $2(|A| \geq 1)$

Select a random search agent $\left(\mathrm{X}_{\text {rand }}\right)$

Update the position of current search agent

end if 2

else if $1(p \geq 0.5)$

Update the position of current search agent

end if1

end for

Check if any search agent goes beyond the search space and amend it

Evaluate the fitness of each search agent

Update $\mathrm{X}^{*}$ if there is a better solution

$\mathrm{t}=\mathrm{t}+1$

end while

Return $\mathrm{X}^{*}$

\section{Test smart grid: at a glance}

To validate the efficacy of the proposed methods, DSM strategies are tested on two areas of smart grid to be tested, each area has deferred types of consumers; namely residential and commercial consumers. In this study, the main goal is to lower consumers' utility tariff in given areas. Therefore in this study, objective curve were always chosen inversely proportional to electricity market prices. Forecasted loads and energy prices of the advance grid are given in Table 1. The entire network of test smart grid operates at a voltage of $410 \mathrm{~V}$. Each inter-connection link including the link between the smart grid and the main grid has a resistance of $0.003 \mathrm{pu}$, a reactance of $0.01 \mathrm{pu}$ and maximum power transfer limit of $500 \mathrm{KVA}$. Length of the links in the residential micro grid is $2 \mathrm{~km}$ and in the commercial micro grids is $3 \mathrm{~km}$. The maximum demand used in each area is $1.5 \mathrm{MW}$ and $2 \mathrm{MW}$ respectively.

Each area of grid has several types of controllable devices, details given as follows. 
Table 1 Forecasted loads and energy prices

\begin{tabular}{|c|c|c|c|}
\hline \multirow[t]{2}{*}{ Time (h) } & \multirow{2}{*}{$\begin{array}{l}\text { Electricity price } \\
\text { (Cent/KWh) }\end{array}$} & \multicolumn{2}{|c|}{ Forecasted load (KW) } \\
\hline & & $\begin{array}{l}\text { Residential } \\
\text { microgrid }\end{array}$ & $\begin{array}{l}\text { Com- } \\
\text { mercial } \\
\text { microgrid }\end{array}$ \\
\hline $8-9$ & 12 & 12.2 & 15.4 \\
\hline $9-10$ & 9.19 & 11.9 & 19.2 \\
\hline $10-11$ & 12.3 & 11.9 & 24.1 \\
\hline $11-12$ & 20.7 & 13.5 & 26 \\
\hline $12-13$ & 26.8 & 13.7 & 27.9 \\
\hline $13-14$ & 27.4 & 12.7 & 27.9 \\
\hline $14-15$ & 13.8 & 12.4 & 27.9 \\
\hline $15-16$ & 17.3 & 11.4 & 26.5 \\
\hline $16-17$ & 16.4 & 11.1 & 26 \\
\hline 17-18 & 9.83 & 15.9 & 27.9 \\
\hline $18-19$ & 8.63 & 20.3 & 30.3 \\
\hline $19-20$ & 8.87 & 22.2 & 25 \\
\hline $20-21$ & 8.35 & 22.7 & 21.6 \\
\hline $21-22$ & 16.4 & 20.9 & 18.3 \\
\hline $22-23$ & 16.2 & 17.4 & 15.4 \\
\hline $23-24$ & 8.87 & 12.7 & 9.62 \\
\hline $24-1$ & 8.65 & 7.93 & 6.73 \\
\hline $1-2$ & 8.11 & 6.87 & 6.25 \\
\hline $2-3$ & 8.25 & 6.08 & 6.25 \\
\hline $3-4$ & 8.1 & 5.81 & 6.73 \\
\hline $4-5$ & 8.14 & 4.49 & 7.22 \\
\hline $5-6$ & 8.13 & 4.49 & 7.22 \\
\hline $6-7$ & 8.34 & 6.87 & 7.22 \\
\hline $7-8$ & 9.35 & 8.99 & 11.1 \\
\hline
\end{tabular}

Table 2 Data of controllable devices in the residential area

\begin{tabular}{|c|c|c|c|c|}
\hline \multirow[t]{2}{*}{ Device type } & \multicolumn{3}{|c|}{ Hourly load of device (KW) } & \multirow{2}{*}{$\begin{array}{l}\text { Number } \\
\text { of devices }\end{array}$} \\
\hline & $\mathrm{I}(\mathrm{h})$ & II (h) & III (h) & \\
\hline Cloth dryer & 1.2 & & & 189 \\
\hline Dish washer & 0.7 & & & 288 \\
\hline Washing machine & 0.5 & 0.4 & & 268 \\
\hline Oven & 1.3 & & & 279 \\
\hline Iron & 1 & & & 340 \\
\hline Vacuum cleaner & 0.4 & & & 158 \\
\hline Fan & 0.2 & 0.2 & 0.2 & 288 \\
\hline Kettle & 2 & & & 406 \\
\hline Toaster & 0.9 & & & 48 \\
\hline Rice cooker & 0.85 & & & 59 \\
\hline Hair dryer & 1.5 & & & 58 \\
\hline Blender & 0.3 & & & 66 \\
\hline Frying pen & 1.1 & & & 101 \\
\hline Coffee maker & 0.8 & & & 56 \\
\hline Total & & & & 2604 \\
\hline
\end{tabular}

Table 3 Data of controllable devices in the commercial area

\begin{tabular}{lllll}
\hline Type of device & \multicolumn{3}{l}{ Hourly load of device (KW) } & $\begin{array}{l}\text { Number } \\
\text { of devices }\end{array}$ \\
\cline { 2 - 3 } & $\mathrm{I}(\mathrm{h})$ & $\mathrm{II}(\mathrm{h})$ & $\mathrm{III}(\mathrm{h})$ & \\
\hline Water dispenser & 2.5 & & 156 \\
Dryer & 3.5 & & 117 \\
Kettle & 3 & 2.5 & & 123 \\
Oven & 5 & & 77 \\
Coffee maker & 2 & 2 & & 99 \\
Fan & 3.5 & 3 & & 93 \\
Air conditioner & 4 & 3.5 & 3 & 56 \\
Lights & 2 & 1.75 & 1.5 & 87 \\
Total & & & & 808 \\
\hline
\end{tabular}

\section{A. Residential area}

Residential area can be identified by small power rating and short time operation. Table 2 shows different devices with their consumption figures. Residential area held 14 types of 2604 devices according to their applications.

\section{B. Commercial area}

Commercial area has devices, which have higher ratings and long time operation in comparison of residential area. The consumption figures of devices are given in Table 3 . Commercial area held 08 types of 808 devices according to their applications.

\section{Results and discussion}

Simulation results depicted in figures and tables show that the used DSM strategies have capacity to bring the final utilization curve near to objective curve. The proposed algorithm handled the several numbers of controllable devices with better efficacy. In this article three different DSM techniques are implemented on residential and commercial areas.

\subsection{Strategic conservation}

Strategic conservation aims to gain optimization at customer premises for load shape using DLC techniques. The distribution side management system has considered for long term reduction in a network. More efficient devices and appliances are used to decrease the overall energy consumption, which is very important globally. It's implemented only for residential and commercial areas.

The simulation results derived from residential area by strategic conservation technique are given in Fig. 5 . Table 4 shows the utility electricity bill of the residential 
Fig. 5 Strategic conservation results of the residential area

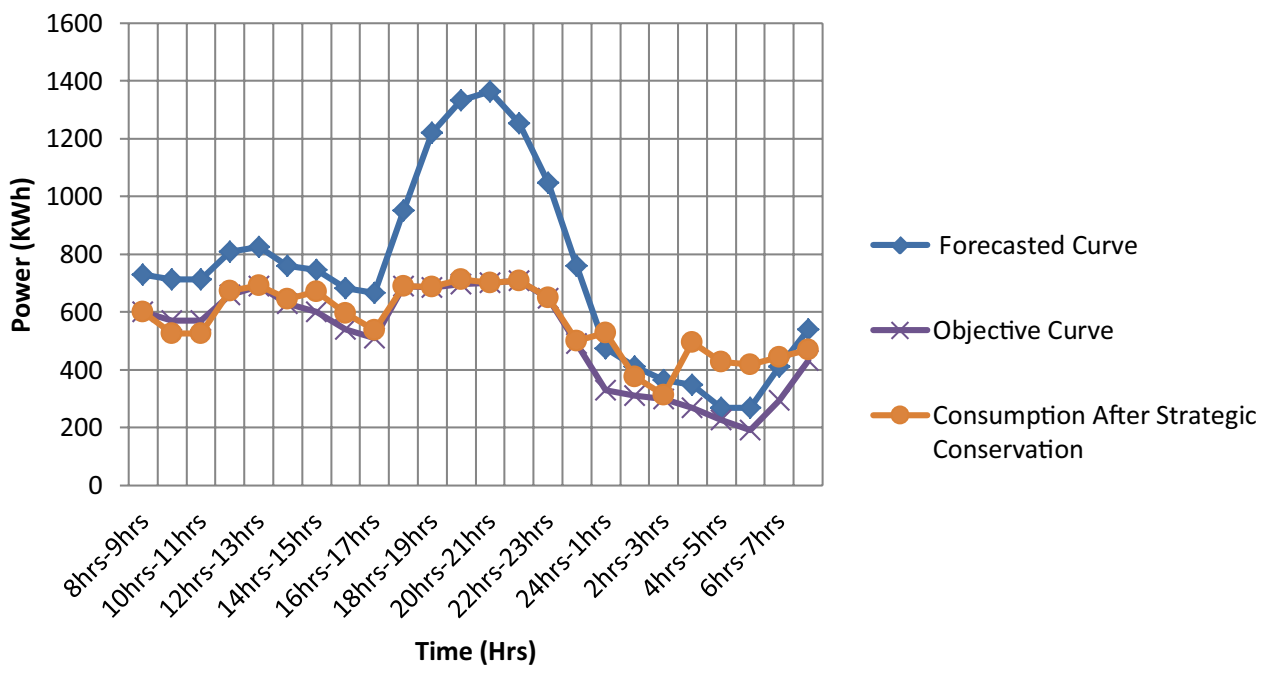

\begin{tabular}{lllll}
\hline Area & Algorithm & $\begin{array}{l}\text { Cost without DSM } \\
\text { in USD }\end{array}$ & Cost with DSM in USD & $\begin{array}{l}\text { Percentage } \\
\text { reduction }\end{array}$ \\
\hline $\begin{array}{l}\text { Reduction in operational cost } \\
\text { Residential }\end{array}$ & WOA & 2302.87928 & 1778.137199 & 22.786 \\
& BBO [34] & 2302.87928 & 1778.650989 & 22.764 \\
& SMO [33] & 2302.88 & 1780.463 & 22.685 \\
Commercial & WOA & 3626.6396 & 3075.120382 & 15.207 \\
& BBO [34] & 3626.6396 & 3076.034452 & 15.182 \\
\hline
\end{tabular}

Fig. 6 Strategic conservation results of the commercial area

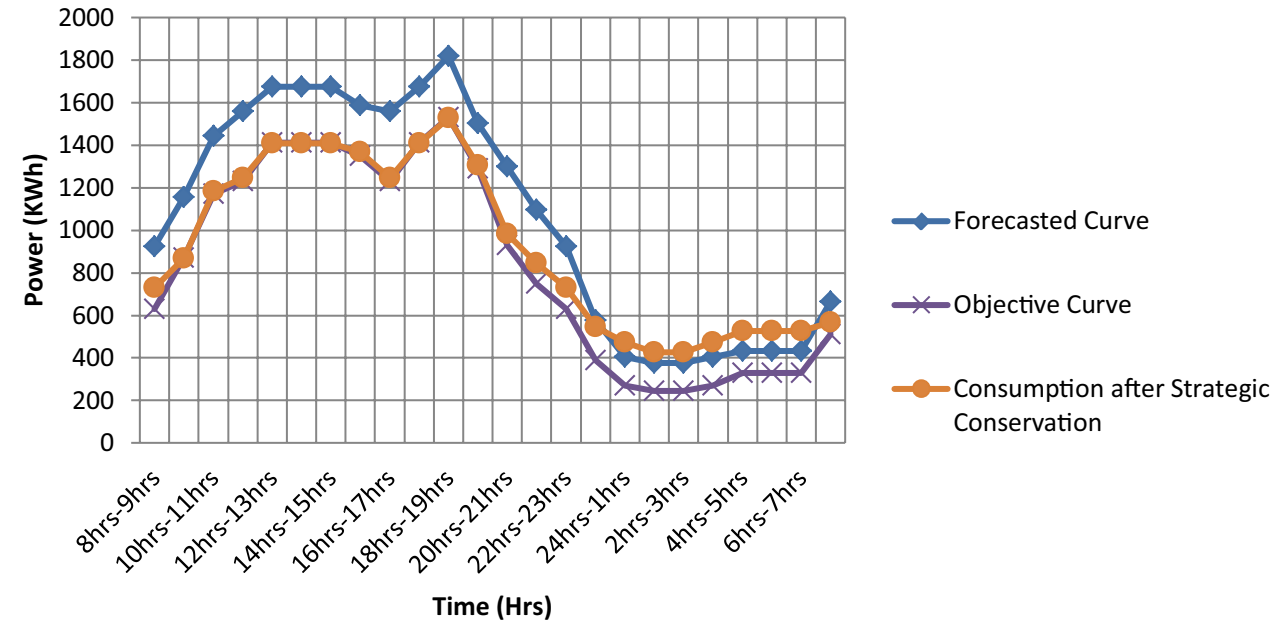

area which has a considerable reduction from $\$ 2302.88$ to $\$ 1780.04$ with strategic conservation technique, which results about $22.78 \%$ reduction in the operation cost using WOA and for the commercial area, from $\$ 3626.63$ to $\$ 3075.12$, results in lowering the operation cost by $15.20 \%$ using WOA. On other side reduction in the operation cost using BBO and SMO are given by $22.764 \%$ and $22.685 \%$ respectively, for residential consumers and for commercial consumers BBO gives $15.921 \%$ reduction in cost, which shows the WOA gives the better results. Table 4 gives simulation results from the proposed DSM technique for residential and commercial areas of future smart grid. The used appeal has ability to fulfill the objective in these areas, also associated with savings in utility tariff. Typically, DSM results give better efficacy, when a number of devices in particular area also associated with control mechanism.

The simulation results obtained for commercial area by strategic conservation technique are given in Fig. 6 . 
Table 5 Reduction in peak demand in strategic conservation

\begin{tabular}{lllll}
\hline Area & Algorithm & $\begin{array}{l}\text { Peak load } \\
\text { without DSM } \\
(\mathrm{KW})\end{array}$ & $\begin{array}{l}\text { Peak load } \\
\text { with DSM } \\
(\mathrm{KW})\end{array}$ & $\begin{array}{l}\text { Percentage } \\
\text { reduction }\end{array}$ \\
\hline $\begin{array}{l}\text { Reduction in peak demand } \\
\text { Residential }\end{array}$ & WOA & 1363.6 & 701.8242 & 48.531 \\
& BBO [34] & 1363.6 & 709.5279845 & 47.966 \\
& SMO [33] & 1363.6 & 703.7646662 & 48.381 \\
Commercial & WOA & 1818.2 & 1528.620662 & 15.926 \\
& BBO [34] & 1818.2 & 1528.710662 & 15.921 \\
\hline
\end{tabular}

Fig. 7 Peak clipping results of the residential area

Table 6 Reduction in operational cost in peak clipping

Fig. 8 Peak clipping results of the commercial area
Effective path of demand side provides several benefits; these are spread out for end users and utilities also. Reduction in peak demand is one of them. Table 5 presents peak demand with and without strategic conservation technique for the residential and commercial areas. It observed that the proposed technique reduces peak demand for residential area, from 1363.60 to $701.82 \mathrm{KW}$, resulting in about $48.53 \%$ reduction in the peak demand and for commercial area, from 1818.2 to $1528.62 \mathrm{KW}$, resulting in about $15.92 \%$ reduction in the peak demand using WOA. On other side reduction in the peak demand using BBO and SMO are given by $47.966 \%$ and $48.381 \%$ respectively

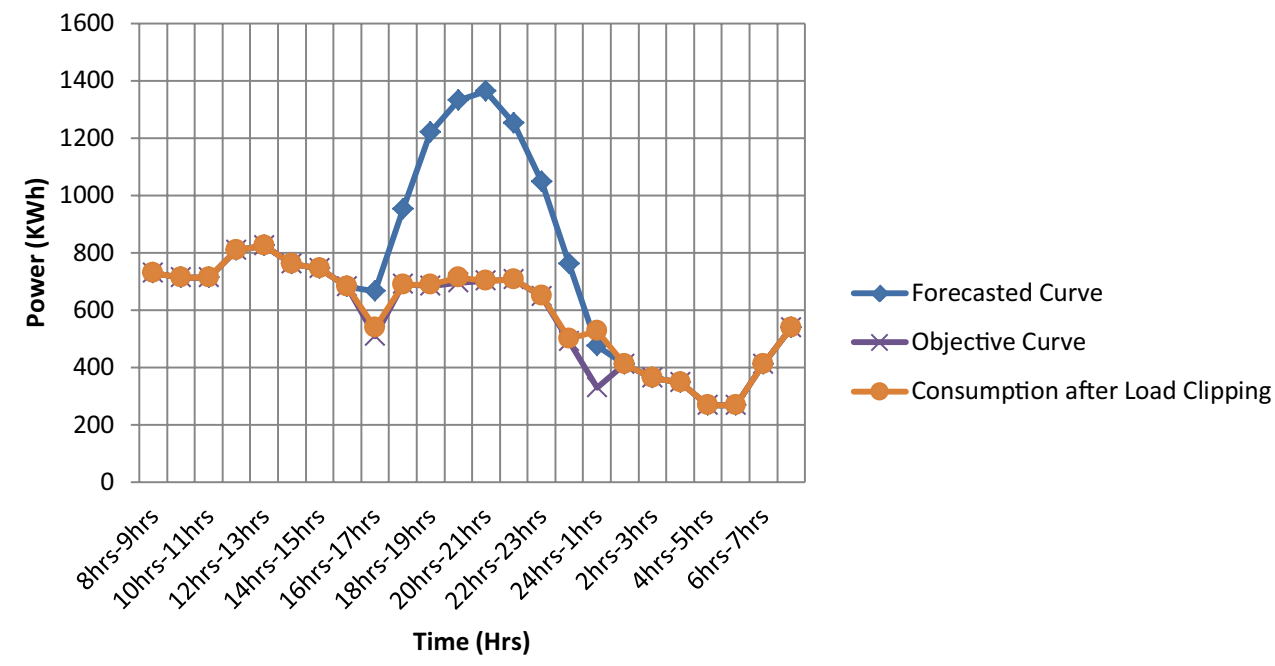

\begin{tabular}{|c|c|c|c|c|}
\hline Area & Algorithm & $\begin{array}{l}\text { Cost without DSM } \\
\text { in USD }\end{array}$ & Cost with DSM in USD & $\begin{array}{l}\text { Percentage } \\
\text { reduction }\end{array}$ \\
\hline \multicolumn{5}{|c|}{ Reduction in operational cost } \\
\hline \multirow[t]{2}{*}{ Residential } & WOA & 2302.87928 & 1927.419823 & 16.30 \\
\hline & BBO [34] & 2302.87928 & 1928.582182 & 16.25 \\
\hline \multirow[t]{2}{*}{ Commercial } & WOA & 3626.6396 & 3040.652438 & 16.15 \\
\hline & BBO [34] & 3626.6396 & 3042.100719 & 16.11 \\
\hline
\end{tabular}

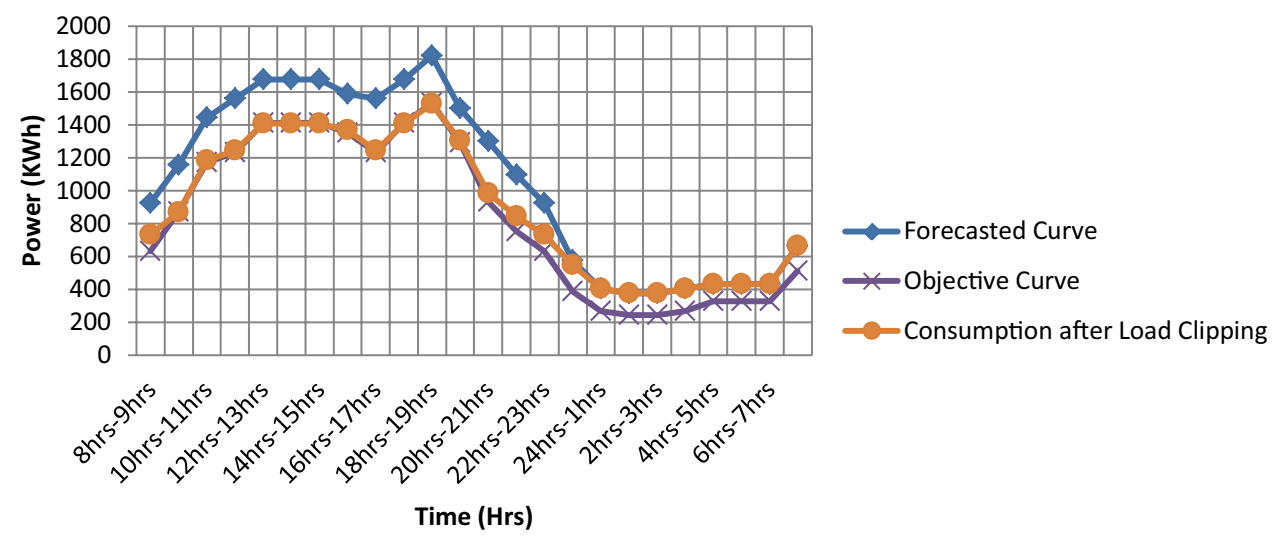


Table 7 Reduction in peak demand in peak clipping

\begin{tabular}{|c|c|c|c|c|}
\hline Area & Algorithm & $\begin{array}{l}\text { Peak load } \\
\text { without DSM } \\
(\mathrm{KW})\end{array}$ & $\begin{array}{l}\text { Peak load } \\
\text { with DSM } \\
(\mathrm{KW})\end{array}$ & $\begin{array}{l}\text { Percentage } \\
\text { reduction }\end{array}$ \\
\hline \multicolumn{5}{|c|}{ Reduction in peak demand } \\
\hline \multirow[t]{2}{*}{ Residential } & WOA & 1363.6 & 701.8242 & 48.53 \\
\hline & $\mathrm{BBO}[34]$ & 1363.6 & 701.7192639 & 48.52 \\
\hline \multirow[t]{2}{*}{ Commercial } & WOA & 1818.2 & 1528.620662 & 15.92 \\
\hline & BBO [34] & 1818.2 & 1530.428544 & 15.82 \\
\hline
\end{tabular}

for residential consumers and for commercial consumers BBO gives $15.921 \%$ reduction in peak demand, which shows the WOA is better than both in this case. Reduction in peak demand enhances grid stability by lowering the total utility cost and level of carbon emission. Additionally, this will foremost reason to avoid the infrastructure cost in forms of generation units, transmission lines and distribution networks.

\subsection{Peak clipping}

This technique focused on lowering the peak load to avert the anxiety of peak demand for increasing the safety and stability of smart grid. Peak clipping is a DLC method for reduction in peak loads. It has one restriction that it's only applicable for residential and small commercial levels. Load clipping window for residential consumers is for $9 \mathrm{~h}$ i.e. it lies between 16:00 to 01:00 $\mathrm{h}$ time window and for commercial consumers it lies between 08:00 to $24: 00 \mathrm{~h}$ time window.

The simulations obtained in residential area from peak clipping technique are given in Fig. 7. Table 6 shows the electricity tariff of residential area lowered from $\$ 2302.88$ to $\$ 1927.41$ with peak clipping technique and gives about $16.30 \%$ reduction in the operation cost and for commercial premises area, it's vary from $\$ 3626.6396$ to $\$ 3040.65$, resulting about $16.15 \%$ reduction in the operation cost using WOA. On other side reduction in the operation cost using $\mathrm{BBO}$ are given by $16.25 \%$ and $16.11 \%$ for residential consumers and commercial consumers respectively.

The simulation results obtained for commercial area by peak clipping technique are given in Fig. 8.
Fig. 9 Load shifting results of the residential area

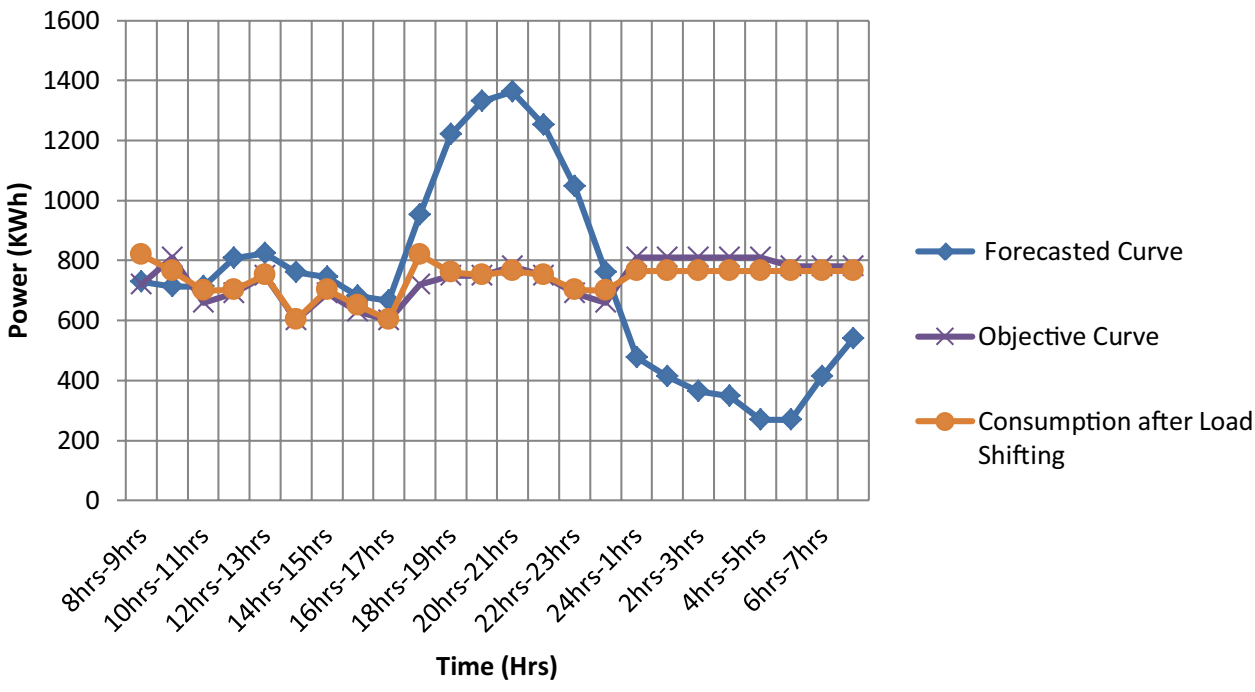

\begin{tabular}{lllll}
\hline Area & Algorithm & $\begin{array}{l}\text { Cost without } \\
\text { DSM in USD }\end{array}$ & Cost with DSM in USD & $\begin{array}{l}\text { Percentage } \\
\text { reduction }\end{array}$ \\
\hline $\begin{array}{l}\text { Reduction in operational cost } \\
\text { Residential }\end{array}$ & WOA & 2302.87928 & 2163.483437 & 6.05 \\
& BBO [34] & 2302.87928 & 2185.32 & 5.10 \\
& Evolutionary algorithm [32] & 2302.87928 & 2188.30 & 5.0 \\
Commercial & 3626.6396 & 3381.390687 & 6.76 \\
& WOA & 3626.6396 & 3432.9453 & 5.34 \\
& BBO [34] & 3626.6396 & 3424.30 & 5.8 \\
\hline
\end{tabular}

Table 8 Reduction in operational cost in load shifting
SN Applied Sciences 
Fig. 10 Load shifting results of the commercial area

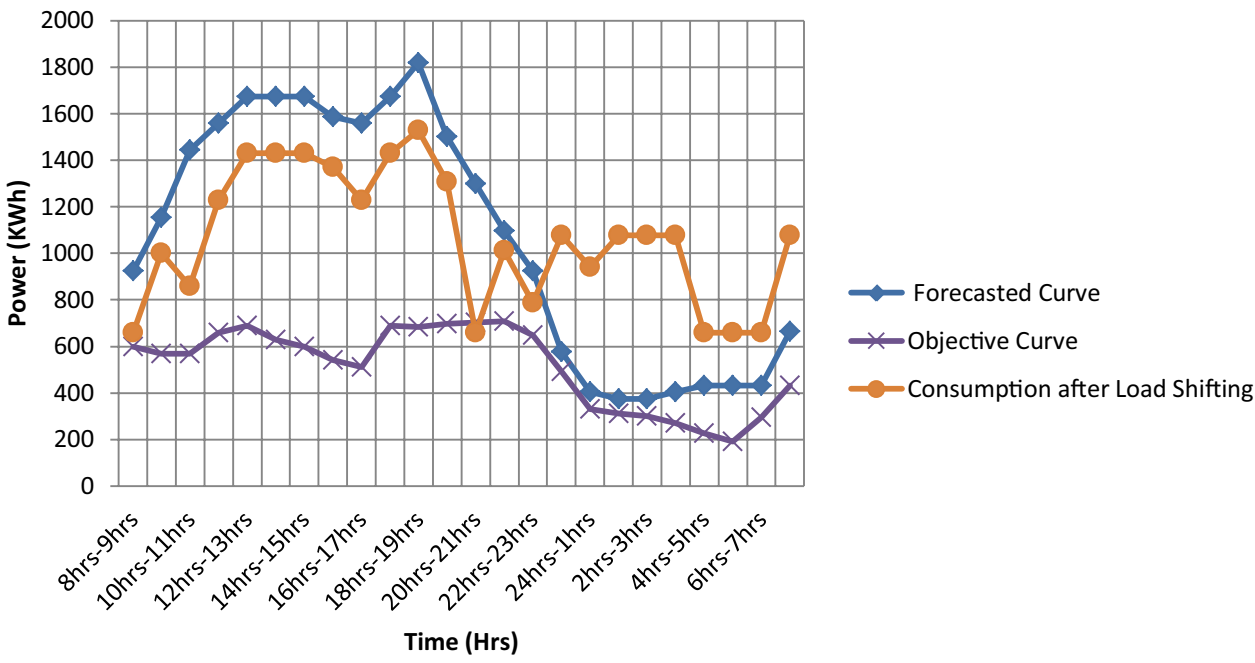

Table 9 Reduction in peak demand in load shifting

\begin{tabular}{lllll}
\hline Area & Algorithm & $\begin{array}{l}\text { Peak load without } \\
\text { DSM (KW) }\end{array}$ & $\begin{array}{l}\text { Peak load with } \\
\text { DSM (KW) }\end{array}$ & $\begin{array}{l}\text { Percentage } \\
\text { reduction }\end{array}$ \\
\hline $\begin{array}{l}\text { Reduction in peak demand } \\
\text { Residential }\end{array}$ & WOA & 1363.6 & 764.9999882 & 43.89 \\
& BBO [34] & 1363.6 & 775.2243 & 43.14 \\
& Evolutionary algorithm [32] & 1363.6 & 1114.4 & 18.3 \\
Commercial & 1818.2 & 1528.620662 & 15.92 \\
& WOA & 1818.2 & 1541.974484 & 15.19 \\
& BBO [34] & 1818.2 & 1485.2 & 18.3 \\
& Evolutionary algorithm [32] & & & \\
\end{tabular}

Table 7 depicted the peak demand with and without the proposed technique for the residential and commercial areas. The proposed technique curtails the peak load demand for residential area, from 1363.60 to $701.82 \mathrm{KW}$, resulting in about $48.53 \%$ reduction in the peak demand and for commercial area, from 1818.2 to $1528.62 \mathrm{KW}$, resulting in about $15.92 \%$ reduction in the peak demand using WOA. On other side reduction in the peak demand using BBO are given by $48.52 \%$ and $15.82 \%$ respectively for residential consumers and for commercial consumers, which shows the WOA is better than both in this case.

\subsection{Load shifting}

Load shifting is globally applied load management technique in current smart grid network and it shifts load demand from peak period to off peak period.

The simulations obtained for residential area by load shifting technique are given in Fig. 9. Table 8 shows total utility bill of residential area lowers from $\$ 2302.88$ to $\$ 2163.48$ with shifting, resulting about $6.05 \%$ reduction in the operation cost and for the commercial area, from $\$ 3626.6396$ to $\$ 3381.39$, resulting about $6.76 \%$ reduction in the operation cost using WOA. Table 8 shows that WOA gives improved results in compare to results yield from Evolutionary Algorithm [32] in term of reduction in the operation cost. On other side reduction in the operation cost using BBO are given by $5.10 \%$ and $5.34 \%$ for residential consumers and commercial consumers respectively.

The simulations obtained for commercial area by load shifting are given in Fig. 10. Table 9 shows the peak demands with and without load shifting method for the residential and commercial areas. The proposed technique minimizes the peak load demand for residential area, from 1363.60 to $764.99 \mathrm{KW}$, resulting in about $43.89 \%$ reduction in the peak demand and for commercial area, from 1818.2 to $1528.62 \mathrm{KW}$, resulting in about $15.92 \%$ reduction in the peak demand using WOA. Table 9 shows that WOA gives improved results in compare to results yield from Evolutionary Algorithm [32] in term of reduction in peak demand. On other side reduction in the peak demand using BBO are given by $43.14 \%$ and $15.19 \%$ respectively for residential consumers and for commercial consumers. Table 10 shows the errors in objective function in WOA for $24 \mathrm{~h}$, which gives the four standards statistical parameters of the objective function values calculated from the 


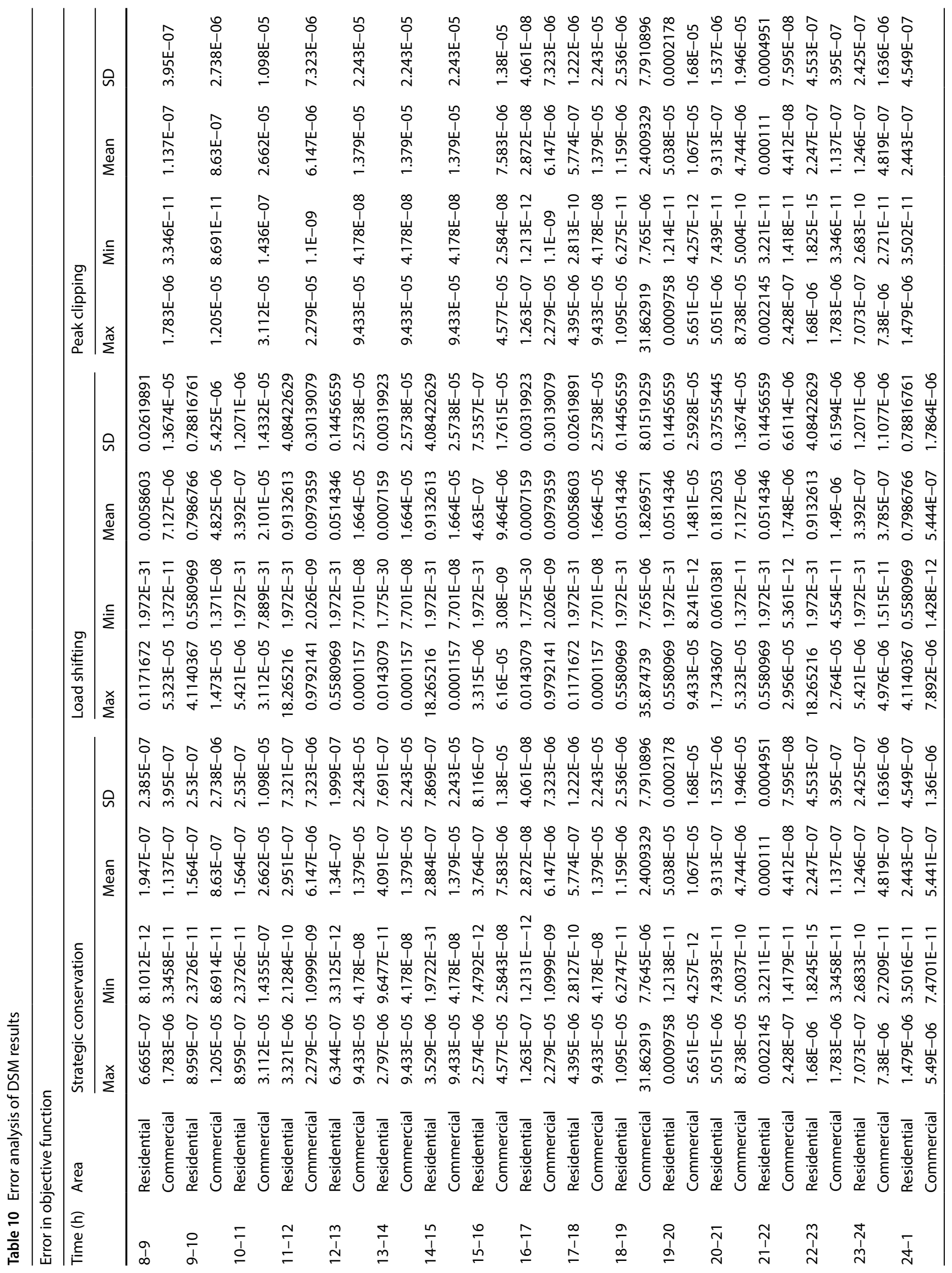




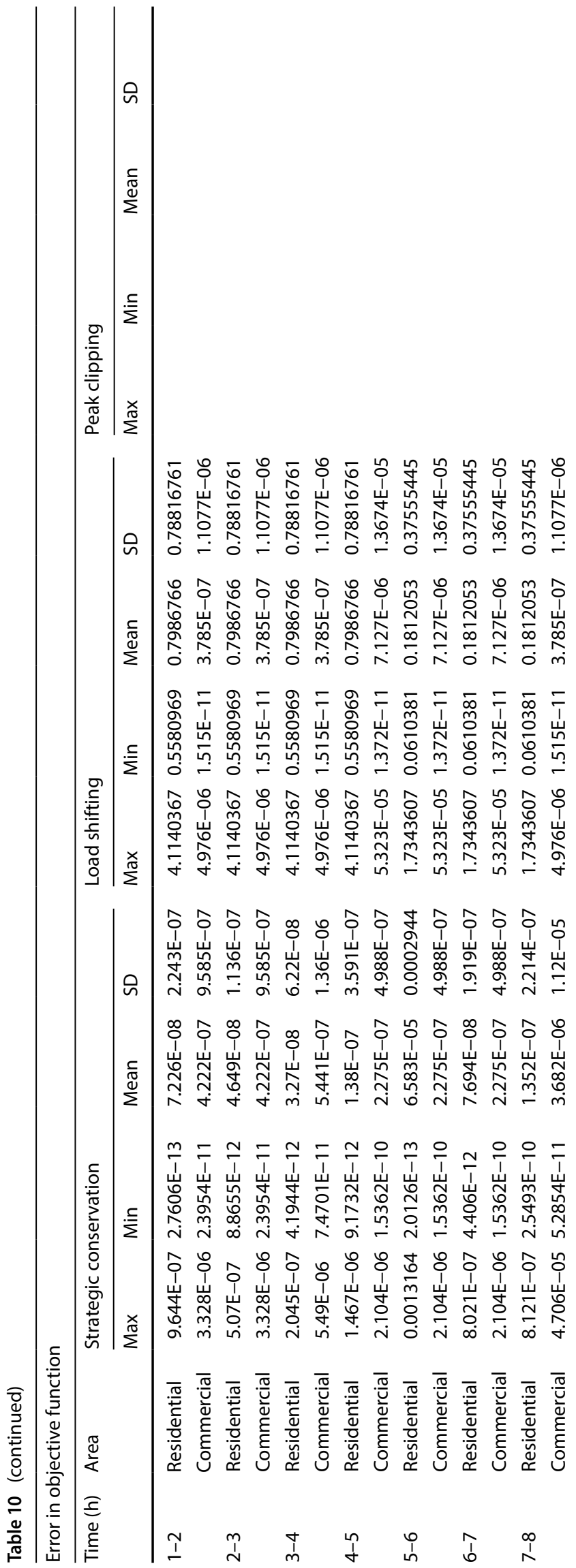

independent runs namely; Max, Min, Mean and Standard Deviation.

\section{Conclusion}

Based on the results obtained from numerical simulations, it is concluded that DSM has become necessary and now a days it has become a unique trendsetter for evolvement of smart grid. The results and analysis lead to the following conclusions:

1. For residential and commercial users the energy demand curve depicted more consumption in comparison of residential area.

2. WOA proved its efficacy for strategic conservation, peak clipping and load shifting. Tables 4, 5, 6, 7, 8 and 9 show the results yield from SMO [33], BBO [34] and Evolutionary Algorithm [32] in term of reduction in operational cost and peak demand. It has been observed that results are competitive.

3. For load shifting, Tables 8 and 9 shows that WOA gives improved results in compare to results yield from Evolutionary Algorithm [32] in term of reduction in operational cost and peak demand.

4. According to new research trend; it is identified or analyzed that with assistance of advance technologies and hybrid programs, Distributed Energy Resources (DER) focuses on the real operations and applications.

5. DR offers easiness for network's management and also finding the solution of different quirk with complex steadfast issues. In markets this new trend is focused towards benefits of users as well as operator.

6. DR participants are rewarded using PBP and IBP, but hybrid and complementary strategy is providing better energy management path with combination of price-based and incentive-based.

It will be interesting to see how new variants of WOA respond to this problem. A comparative analysis of the variants and different algorithms along with the proposal of supervised learning framework are kept for future research work.

\section{Compliance with ethical standards}

Conflict of interest The authors declare that they have no conflict of interest. 


\section{References}

1. Li Q, Zhou M (2011) The future-oriented grid-smart grid. J Comput 6(1):98-105

2. Agrawal P (2006) Overview of DOE microgrid activities. In: Symposium on microgrid, Montreal, June, vol 23

3. Albadi MH, El-Saadany EF (2008) A summary of demand response in electricity markets. Electric Power Syst Res 78(11):1989-1996

4. Herter K, McAuliffe P, Rosenfeld A (2007) An exploratory analysis of California residential customer response to critical peak pricing of electricity. Energy 32(1):25-34

5. Piette MA, Sezgen O, Watson DS, Motegi N, Shockman C, Ten Hope $L$ (2005) Development and evaluation of fully automated demand response in large facilities, CEC-500-2005-013, LBNL-55085

6. Valero S, Ortiz M, Senabre C, Alvarez CAAC, Franco FJG, Gabaldon A (2007) Methods for customer and demand response policies selection in new electricity markets. IET Gener Transm Distrib 1(1):104-110

7. Sezgen O, Goldman CA, Krishnarao P (2007) Option value of electricity demand response. Energy 32(2):108-119

8. Albadi MH, El-Saadany EF (2007) In: 2007 IEEE power engineering society general meeting. IEEE, pp 1-5

9. Goel L, Wu Q, Wang P (2006) Reliability enhancement of a deregulated power system considering demand response. In: 2006 IEEE power engineering society general meeting. IEEE, $p 6$

10. Spees K, Lave LB (2007) Demand response and electricity market efficiency. Electr J 20(3):69-85

11. Barbose G, Goldman C, Neenan B (2004) A survey of utility experience with real time pricing, Berkeley, LBNL-54238

12. Caves D, Eakin K, Faruqui A (2000) Mitigating price spikes in wholesale markets through market-based pricing in retail markets. Electr J 13(3):13-23

13. DeMeo EA, Grant W, Milligan MR, Schuerger MJ (2005) Wind plant integration [wind power plants]. IEEE Power Energy Mag 3(6):38-46

14. Smith JC, Milligan MR, DeMeo EA, Brian P (2007) Utility wind integration and operating impact state of the art. IEEE Trans Power Syst 22(3):900-908

15. DeMeo EA, Jordan GA, Kalich C, King J, Milligan MR, Murley C, Oakleaf B, Schuerger MJ (2007) Accommodating wind's natural behavior. IEEE Power Energy Mag 5(6):59-67

16. Papavasiliou A, Oren SS Coupling wind generators with deferrable loads. In: 2008 IEEE energy 2030 conference. IEEE, pp 1-7

17. Sioshansi R (2009) Evaluating the impacts of real-time pricing on the cost and value of wind generation. IEEE Trans Power Syst 25(2):741-748

18. Dietrich K, Latorre JM, Olmos L, Ramos A (2011) Demand response in an isolated system with high wind integration. IEEE Trans Power Syst 27(1):20-29

19. Cheng $Y$, Dong N, Ren $Y$ (2011) Investigation on electric load peak and valley characters and demand response evaluation based on spectral analysis. In: 2011 International conference on advanced power system automation and protection, vol 2. IEEE, pp 1258-1262

20. Wu J, Ai X, Zhao Y, Wu D (2013) Research on modeling and appliance of a new price mechanism demand response. In: 2013 IEEE PES Asia-Pacific power and energy engineering conference (APPEEC). IEEE, pp 1-5

21. Abdullah MM, Dwolatzky B (2010) Demand-side energy management performed using direct feedback via mobile systems: enables utilities to deploy consumer based demand response programs. In: 2010 IEEE international energy conference. IEEE, pp 172-177
22. Mathieu JL, Callaway DS, Kiliccote S (2011) Examining uncertainty in demand response baseline models and variability in automated responses to dynamic pricing. In: 2011 50th IEEE conference on decision and control and european control conference. IEEE, pp 4332-4339

23. Panapakidis IP, Frantza SI, Papagiannis GK (2014) Implementation of price-based demand response programs through a load pattern clustering process $53-58$

24. Andreou GT, Symeonidis AL, Diou C, Mitkas PA, Labridis DP (2012) A framework for the implementation of large scale demand response. In: 2012 international conference on smart grid technology, economics and policies (SG-TEP). IEEE, pp 1-4

25. Shipman R, Gillott M, Naghiyev E (2013) SWITCH: case studies in the demand side management of washing appliances. Energy Procedia 42:153-162

26. Khomami HP, Javidi MH (2013) An efficient home energy management system for automated residential demand response. In: 2013 13th international conference on environment and electrical engineering (EEEIC). IEEE, pp 307-312

27. Liu B, Wei Q (2013) Home energy control algorithm research based on demand response programs and user comfort. In: Proceedings of 2013 2nd international conference on measurement, information and control, vol. 2. IEEE, pp 995-999

28. Shen S, Zhao Y, Pang J, Yu W, Wu K (2012) Exploring the use value of air conditioners in residential peak demand response. In: 2012 China international conference on electricity distribution. IEEE, pp 1-5

29. Wu Z, Xia X (2017) A portfolio approach of demand side management. IFAC-PapersOnLine 50(1):171-176

30. Meyabadi AF, Deihimi MH (2017) A review of demand-side management: reconsidering theoretical framework. Renew Sustain Energy Rev 80:367-379

31. Attia HA (2010) Mathematical formulation of the demand side management (DSM) problem and its optimal solution. Cairo University, Giza

32. Logenthiran T, Srinivasan D, Shun TZ (2012) Demand side management in smart grid using heuristic optimization. IEEE Trans Smart Grid 3(3):1244-1252

33. Bansal JC, Sharma H, Jadon SS, Clerc M (2014) Spider monkey optimization algorithm for numerical optimization. Memet Comput 6(1):31-47

34. Simon D (2008) Biogeography-based optimization. IEEE Trans Evol Comput 12(6):702-713

35. Gupta S, Saxena A, Soni BP (2015) Optimal placement strategy of distributed generators based on radial basis function neural network in distribution networks. Procedia Comput Sci 57:249-257

36. Saxena A (2019) A comprehensive study of chaos embedded bridging mechanisms and crossover operators for grasshopper optimisation algorithm. Expert Syst Appl 132:166-188

37. Saxena A, Shekhawat S (2017) Ambient air quality classification by grey wolf optimizer based support vector machine. J Environ Public Health 2017:3131083. https://doi. org/10.1155/2017/3131083

38. Sharma AK, Saxena A, Tiwari R (2016) Optimal placement of svc incorporating installation cost. Int J Hybrid Inf Technol 9(8):289-302

39. Mirjalili S, Lewis A (2016) The whale optimization algorithm. Adv Eng Softw 95:51-67

40. Kaur G, Arora S (2018) Chaotic whale optimization algorithm. J Comput Des Eng 5(3):275-284

41. Elaziz MA, Mirjalili S (2019) A hyper-heuristic for improving the initial population of whale optimization algorithm. Knowl Based Syst 172(2019):42-63

42. Mafarja M, Mirjalili S (2018) Whale optimization approaches for wrapper feature selection. Appl Soft Comput 62:441-453 
43. Chen $H$, Yueting $X$, Wang $M$, Zhao X (2019) A balanced whale optimization algorithm for constrained engineering design problems. Appl Math Model 71:45-59

44. Xiong G, Zhang J, Shi D, He Yu (2018) Parameter extraction of solar photovoltaic models using an improved whale optimization algorithm. Energy Convers Manag 174:388-405

45. Miao Y, Zhao M, Makis V, Lin J (2019) Optimal swarm decomposition with whale optimization algorithm for weak feature extraction from multicomponent modulation signal. Mech Syst Signal Process 122:673-691

46. Elhosseini MA, Haikal AY, Badawy M, Khashan N (2019) Biped robot stability based on an $\mathrm{A}-\mathrm{C}$ parametric whale optimization algorithm. J Comput Sci 31:17-32

47. Ben oualid Medani K, Sayah S, Bekrar A (2018) Whale optimization algorithm based optimal reactive power dispatch: a case study of the Algerian power system. Electric Power Syst Res 163(2018):696-705
48. Sahu PR, Hota PK, Panda S (2018) Power system stability enhancement by fractional order multi input SSSC based controller employing whale optimization algorithm. J Electr Syst Inf Technol 5(3):326-336

49. Sharma S, Bhattacharjee S, Bhattacharya A (2018) Probabilistic operation cost minimization of micro-grid. Energy 148:1116-1139

50. Sun W, Zhang C (2018) Analysis and forecasting of the carbon price using multi-resolution singular value decomposition and extreme learning machine optimized by adaptive whale optimization algorithm. Appl Energy 231:1354-1371

Publisher's Note Springer Nature remains neutral with regard to jurisdictional claims in published maps and institutional affiliations. 